I $5 \mathrm{~m}$. to $45 \mathrm{~m}$. after sunset, and in most cases in a cloudless sky; but that on 1886 June 5 was the reverse in both points. Some notes will be found in NATURE, 1883, A pril and May, for the pillar observed in that year. That seen here partly resembles Fig.4, Plate III. in Symons's Meteorological Marazine, 1871 .

Radcliffe Observatory, Oxford, June 2 I

\title{
The Enemies of the Frog
}

WHEN living at Mackay, Queensland, I frequently observed that the common house-frogs ( $H$. carulea) were injured in the hind-limbs, and on several occasions I would hear them croaking in pain ; but on arrival all I saw would be a wretched exhausted frog weakly hopping away with a wound in the hind-leg, from which the blood would be oozing. Later on I found that rats attack the frogs. The rats catch the frog by the hind-leg, and apparently suck the wound they cause, then let the frog crawl away, attack it and suck it again, and so on until the rat has had enough. I believe the rats suck the blood, because I was never able to discover a frog so attacked on which the flesh had been destroyed.

Mr. W. P. Fletcher, a well-known local naturalist, once gave me the following account of a mantis attacking a frog. It was in the autumn of 1877 , at Rockhampton, Queensland. He was "attracted by hearing the noise of a frog in distress, in the daytime, in some garden-shrubs about 6 feet high; he went to see the cause, and found a green frog about 2 inches long. A green mantis about 5 inches long, with one claw had hold of it across the neck, so that the frog could not move, and the mantis was chewing, ant did chew off, the hind-leg, the blood flowing profu ely." He called Mrs. Fletcher to see them, and then destroyed the mantis, whereon the frog crawled away.

At Lake Elphinstone (100 miles from Mackay) I once found a small frog ( $H$. rubella) in the house in a very exhausted condition; on examination I found a large leech on its tongue. This specimen, with the leech attached, I gave to Mr. Boulenger at the British Museum, where it can be seen.

At Mackay the chief enemies of the frogs appeared to be the snakes and the Agamida. H. LING ROTH

\section{Chronology of Elasticians}

IN forming a chronological list of writers on elasticity I have been unable to ascertain the following dates, which I should be much obliged if any of your readers would kindly supply: Mariotte (né près de Dijon vers 1620, Marie). Is nothing more definite known as to the date of his birth ?

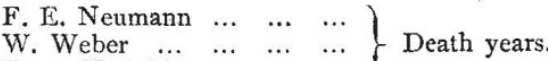

$$
\begin{aligned}
& \text { Eaton Hodgkinson } \quad \ldots . \quad \ldots \text {, } \\
& \begin{array}{lllll}
\text { S. Haughton } & \ldots & \ldots & \ldots & \text {, Birth years. } \\
\text { J. H. Jellett } & \ldots & \ldots & \ldots & \text { ( }
\end{array}
\end{aligned}
$$

University College, London, June 27 KARL PEARson

\section{SOLAR METEOROLOGY1}

SIG. TACCHINI'S detailed report on the various phases of solar activity during the year I 884 deserves, as might be expected from the reputation of its author, most careful attention. Exceptionally fine weather permitted observations of sunspots and faculæ to be made at the Collegio Romano on 307 out of the 365 days, so that the materials accumulated were more than usually abundant. We are thus particularly well informed regarding the symptoms attending the protracted maximum which culminated in February I 884.

This is the more fortunate as that maximum was distinguished by features of special interest. It was delayed considerably beyond the usual term, the interval from the maximum of 1870 being no less than 13.4 in lieu of the normal II'I years. And to this delay corresponded a greatly reduced intensity, in accordance with the law by which the undulations of the curve representing spot-

\footnotetext{
x " Meteorologia Solare." Note di P. Tacchini. Estratto dagli Annali della Meteorologia Italiana, Parte 3, r884. (Roma: Tipografia Metastasio,
}

frequency are low in proportion as they are long. The maximum of 1884 , accordingly, was by much the feeblest which had occurred since I830. It was moreover a hesitating -it might almost be called an abortive-maximum. Some unknown cause apparently interfered with its due and punctual development. Partial anticipatory outbreaks betrayed the tendency, continually repressed, to complete the cycle at the regular epoch, and with the regular expenditure of energy. Now perturbation-of whatever nature -is always instructive : hence Signor Tacchini's laborious statistical results acquire added significance.

They have been gathered along several closely connected lines of research. The various classes of solar surfacephenomena-spots, faculæ, prominences, metallic eruptions-have been studied apart, and the several resulting inferences as to the progress of solar disturbance subsequently confronted. The trifling discrepancies thus revealed show the mutual dependence of no two such species of commotion to be absolute. Each swells or subsides on the whole without immediate or invariable reference to any other, although under the obvious control of some common underlying cause.

Sunspot activity received a notable accession in the beginning of October 1883 , the phase of excitement reaching its acme in the following February, ${ }^{1}$ and persisting until the end of May. Since then, some slight oscillations notwithstanding, it has continually declined. The sun was not, however, observed at Rome to be free from spots on a single day in 1884 . The maximum for prominences occured in March, and they continued exceptionally numerous down to the end of October. In all, 27 I4 were delineated and described in 242 observations with the spectroscope, being at the average rate of II.22 per diem. Sixty metallic eruptions, observed on the same occasions, gave a mean diurnal frequency of 0.248 as against $0^{\circ} \mathrm{I} 7 \mathrm{I}$ for $\mathrm{I} 883$. The richest crop was collected in November 1884, during which month ten eruptions were recorded in sixteen observations. The development of faculæ deviated so markedly from that of spots that their respective fluctuations were at times even inverted. It should also be noted that the mean area per spot in I 884 was of little more than half its value in the preceding year, and that the magnetic instruments at Rome remained throughout comparatively calm

Much valuable information is afforded by Signor Tacchini's careful inquiries as to the distribution on the sun's surface of the different orders of solar phenomena. All these showed, during 1884 , a conspicuous prevalence of activity in the southern hemisphere ; and the inequalityas appears from a note by the same author presented to the Reale Accademia dei Lincei, March 7. I886--became still more striking in the ensuing year. No spot was observed in either hemisphere during 1884 at more than $30^{\circ}$ from the equator; nor on the northern side, during the latter half of the year, at above $20^{\circ}$. With this contraction of the spotted zone coincided a close approach to the equator of the parallel of maximum frequency; and the usual equatorial minimum was both in 1884 and 1885 very imperfectly maintained.

Prominences were plentifully distributed between $60^{\circ}$ north and $50^{\circ}$ south latitude, with maxima between $20^{\circ}$ and $30^{\circ}$. As during the spot-maximum of 1870 , they showed no disposition to avoid the vicinity of the equator; while in $1880,188 \mathrm{I}$, and 1882 , the equatorial minimum of prominences was very marked, and remained perceptible in 1883. Although some rare instances of metallic eruptions were detected in high northern latitudes, they affected chiefly a zone bounded by parallels of $20^{\circ}$. Faculæ occurred predominantly in the same region, and nowhere appeared in latitudes above $50^{\circ}$. On the whole, a concentration towards the equator of the whole range of phenomena was unmistakable, and might be thought to I M. Rudolf Wolf places the maximum in November $288_{3}$. 
correspond with a more advanced stage of the spot-cycle than was indicated by numerical data alone.

Signor Tacchini concludes his memoir with a survey of the vicissitudes of spot-formation during eight yearsfrom January I, 1877, to December 31,1884 . 'The results are graphically exhibited in a set of curves variously derived. No. I is constructed from the daily numbers of spots with their accompanying pores; No. 2 from the record of spots alone; No. 3 shows the frecuency of groups; No. 4 follows the fluctuations of spotted area; No. 5 those of facular extension. All the first four methods agree in fixing the abolute minimum in .Larch 1879 ; Nos 1, 2, and 3 display secondary maxima in September 1880 , March and July 1881 , and March 1882 : the absolute maximum was reached, judging by the statistics of spots and groups (curves 2 and 3 ) in February 1884 ; but in November $188_{3}$, according to those of spots with pores, and spotted area (curves $I$ and 4 ). It is noticeable that the preliminary maxima are largely exaggrerated in proportion to the true maximum, when pores are admitted into the account with spots; while the curve result ing from the simple enumeration of groups is very slightly indented. This last method is regarded by our author as that which should invariably be followed when recent have to be compared with ancient records of sunspots; but no system of observation with the eye can any longer compete with the simpler and surer one of photographic registration.

The curve of facular extension for $1877-84$ is somewhat anomalous. It touched its lowest point in November 1878 , five months previous to the spot-minimum, then sprang up to an absolute maximum in October 1880 . This was followed by a secondary but very considerable rise in September $\mathrm{I} 88 \mathrm{I}$, after which, during two years, a tolerably high average level was maintained. The definitive decline which set in in September 1883 was only partially arrested in May 1884 . The coincidence between the maximum of faculie in September 1880 , and a large and abrupt increase in the formation of pores, just a month earlier, should not be overlooked. It is also remarkable that a maximum of prominences, but slightly inferior to that of 1884 , occurred in 1881 .

The condition of the sun in 1885 is epitomised in the note by Signor Tacchini alrcady referred to. That ycar was, in bis opinion, distinguished as one of continued agitation by the persistent abundance of its various symptoms in the neighbourhood of the equator. A zone of $40^{\circ}$ north and south covered all the spots, and (save one example of each kind) all the facula and metallic cruptions observed. The tranquil or "hydrogenic" description of prominences, on the other hand, figured indifferently in all latitudes. Their general equality of diffusion was but slightly infringed by a southern preponderance; while the frequency in the same hemisphere of spots, faculix, and eruptions was, in each class, almost double that of its northern occurrence. The alternating activity of the solar hemispheres, thus excmplified in one of its most conspicuous phases, is one of the many enigmatical features of solar disturbance.

\section{SEISMOLOGY IN FAPAN ${ }^{1}$}

FOUNDED only in 1879 , the Seismological Socicty of Japan is already able to point to a good record of accomplished work. The Society was happy in the time and the place of its birth. No home could be more fitted to nurse the enthusiasm of the scismologist than one whose foundations are shaken, on the average, a little oftener than once a week. One may take a rather half-hearted interest in other natural phenomena, but, while it lasts, an carthquake certainly commands undivided attention. And the Society came into being just when a few zealous investigators were striving who should

I Transactions of the Scismological Socicty of Japan, vol. viii. (Tokio: Published by the Socity, z88.) be first to solve the problem of obtaining an accurate record of how the ground moves in an earthquake. Lord Byron has described a thunderstorm in the Alps as the joy of the hills "o'er a young earthquake's birth ;" but the joy of the hills, if more loudly expressed, was nothing like so deep as the joy with which the inventor of a new "earthquake machine" felt the first convulsion that came to test its powers. In these congenial conditions it is not surprising that the Society's early volumes record the history of what is nothing less than a new departure in observational seismology: Of late the Society has suffered by the removal from Japan of some of its more active members; but this latest volume of its Transactions gives satisfactory evidence that, while it has not yet lost all its foreign supporters, some of the Japanese themselves are ready to step forward and continue the work. So long as Prof. Milne remains, the Society will not lack material for publication; the present volume, like many of its predecessors, is largely the work of his pen.

The first paper, on "Seismic Experiments," is by Mr. Milne, and contains an account of eight series of experiments on artificial earthquakes, as well as some laboratory work. Part of this work was done in conjunction with Mr. T. Gray, and much of it has already been described in other papers. The vibrations of the ground were produced in some instances by letting fall heavy weights, in others by the use of dynamite. Several observing-stations were selected, at various distances from the source of disturbance, and generally in one straight line with it. At these stations seismographs of various kinds were placed, and Prof. Milne seems to have preferred the horizontal pendulum seismograph of the present writer as an instrument for recording separately two rectangular components of the horizontal motion of the ground. By placing the pair of pendulums so that one recorded vibrations in the direction of the line joining the station with the source, while the other recorded vibrations at right angles to this, Prof. Milne was able to separate without difficulty the normal from the transwerse constituents of the disturbance, and to see the normal vibrations arrive sooner than the transverse vibrations at each station, as the theory of waves in elastic solids requires. In this instrument the two components of horizontal motion are separately recorded on a moving plate of smoked glass. Another instrument was used to record the whole horizontal movement on a fixed plate, and, as might be expected, the diagrams it gave showed first a movement in the line of the source, quickly followed by a confused wriggle of vibrations in all azimuths. By telegraphically connecting the moving plates of the horizontal pendulum seismographs, Prof. Milne endeavoured to determine the interval of time between the arrival of the disturbance at successive stations, and so to infer the velocity of transit. From the results he has concluded that the velocity decreases as the disturbance travels away from the origin, but the figures on which this conclusion is based seem to the present writer to furnish very insufficient evidence. In one series of cxperiments there is, in the average of three pairs of observations, a loss of about 6 per cent. in the velocity between the second and third stations as compared with the velocity between the first and second stations; but, when we examine the individual observations, we find in one case a gain of velocity amounting to I4 per cent. And, on turning to what is apparently the most complete series of automatically-recorded diagrams (which are reproduced in lithographed plates), it is clear that the time-intervals cannot have been measured with the precision necessary to establish this result, still less to justify the further coinclusion that the velocities of normal and transverse waves become more nearly equal as the disturbance spreads. The velocity of transit is, in fact, a term of very vague meaning, unless we can follow an individual wave along its course. As Mr. Milne's 